\title{
Aorta-right atrial tunnel: Clinical presentation, diagnostic criteria, and surgical options
}

\author{
Trushar Gajjar, DNB, ${ }^{a}$ Choudary Voleti, MD, FACS, ${ }^{\text {a }}$ Rekha Matta, MCh, ${ }^{a}$ Ramnath Iyer, DNB, \\ Prabhat Kumar Dash, DM, ${ }^{\mathrm{b}}$ and Neelam Desai, MCh, DNB,
}

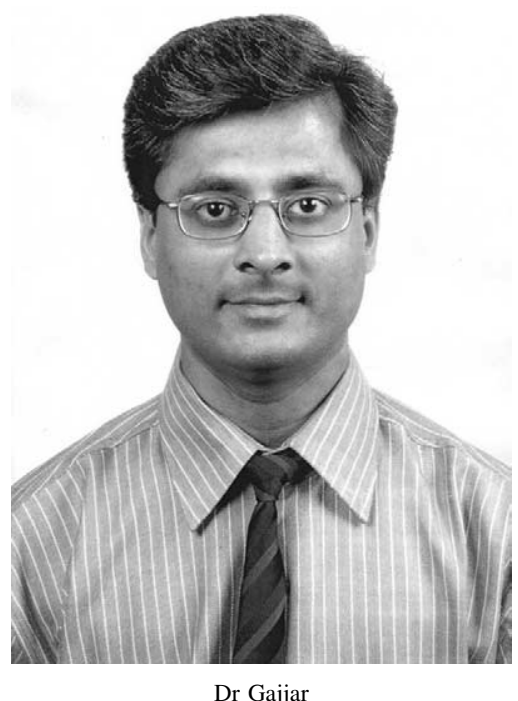

Dr Gajjar
From the Departments of Cardiothoracic and Vascular Surgery, ${ }^{\mathrm{a}}$ and Cardiology, Sri Sathya Sai Institute of Higher Medical Sciences, Prasanthigram, District Anantapur, Andhra Pradesh, India.

Received for publication March 29, 2005; revisions received June 30, 2005; accepted for publication July 12, 2005.

Address for reprints: Trushar Gajjar, DNB, Cardiothoracic and Vascular Surgery Department, Sri Sathya Sai Institute of Higher Medical Sciences, Prasanthigram-515134, District Anantapur, Andhra Pradesh, India (E-mail: trushar_edu@yahoo.co.in).

J Thorac Cardiovasc Surg 2005;130:1287-92 $0022-5223 / \$ 30.00$

Copyright (C) 2005 by The American Association for Thoracic Surgery

doi:10.1016/j.jtcvs.2005.07.021
Objective: Aorta-right atrial tunnel is a rare and distinct congenital anomaly. To the spectrum of aorta-right atrial communications, we want to add this separate entity of aorta-right atrial tunnel by presenting the clinical features, morphologic aspects, diagnostic criteria, surgical techniques, and outcome in various clinical settings for better understanding of this developmentally intriguing, clinically complex, and therapeutically challenging disorder.

Methods: From June 1994 through October 2004, 9 patients were treated for aorta-right atrial tunnel at our institution. Ages ranged from 9 to 45 years. There were 5 male subjects and 4 female subjects. Morphologically, 2 types of tunnels were identified in relationship to the ascending aorta: the anterior type in 3 patients and the posterior type in 6 patients. In all patients the diagnosis was established by means of 2-dimensional echocardiography and transesophageal echocardiography and confirmed by means of angiography. Eight patients were treated surgically, and 1 patient was treated with coil embolization. Postoperative echocardiograms obtained for all patients before discharge confirmed complete obliteration of the tunnel.

Results: One patient died perioperatively, and the other 8 patients were discharged in stable condition. During follow-up at 3 months, 6 months, and 1 year, all patients were in New York Heart Association class I, and echocardiography showed no residual shunts.

Conclusions: In patients with aorta-right atrial tunnel, 2-dimensional echocardiography and transesophageal echocardiography are enough to establish clinical diagnosis, but ascending aortography is necessary to differentiate from more common clinical conditions, like ruptured sinus of Valsalva aneurysm and coronary cameral fistula. The rarity of this condition is established by the fact that during the same period of time, we have treated in our institution 66 cases of ruptured sinus of Valsalva aneurysm, which is the most common aorta-right atrial communication. Treatment options are simple ligation or ligation with implantation of coronary ostium or coil embolization. The location of the coronary ostium dictates technical details. Follow-up reveals excellent functional recovery.

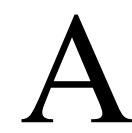
orta-right atrial tunnel (ARAT) is an abnormal tubular extracardiac communication between the ascending aorta and the right atrium. It is a very rare condition. The first case was described in 1980 by Otero Coto and colleagues. ${ }^{1}$ Sporadic case reports of this disease make it vague and ill understood. Because only a few case reports are encountered in the literature, definitive surgical intervention and long-term outcome are not defined. ${ }^{1-5}$

The purpose of this report is to describe in detail the clinical presentation, morphologic aspects, diagnostic modalities, and treatment options to consolidate the 


\section{Abbreviations and Acronyms \\ 2D = 2-dimensional \\ ARAT $=$ aorta-right atrial tunnel \\ NYHA $=$ New York Heart Association}

understanding of this infrequently encountered distinct anomaly.

\section{Methods}

From June 1994 through October 2004, a total of 9 patients with ARAT were treated in our institution. Ages ranged from 9 to 45 years (mean, 20.2 years), with a male/female ratio of 5:4. All patients were symptomatic. Clinical presentation included one or more of the following complaints. Five patients had shortness of breath, of whom 3 were in New York Heart Association (NYHA) class III and 2 were in NYHA class II. Four patients presented with palpitation. Recurrent respiratory tract infection was present in 3 patients, angina of NYHA class II was present in 2 patients, atypical chest pain was present in 2 patients, and easy fatigability was present in 2 patients. Physical examination revealed a continuous murmur at the right parasternal border in the third, fourth, and fifth intercostal spaces in all 9 patients. Initial chest radiography showed cardiomegaly in all patients, with cardiothoracic ratios ranging from $55 \%$ to $80 \%$ and increased pulmonary vascularity. Electrocardiography showed sinus rhythm, normal axis, and right ventricular hypertrophy, with strain pattern in all patients. Twodimensional (2D) echocardiography and Doppler scanning showed a tunnel-like structure with continuous Doppler signals from the left coronary sinus to the right atrium in 6 patients and from the right coronary sinus to the right atrium in the remaining 3 patients (Figure 1). Cardiac catheterization and angiography were performed in all patients. Cardiac catheterization showed a step up at the right atrial level ranging from $77 \%$ to $92.9 \%$ and left-to-right shunt ranging from $1.3: 1$ to $6.3: 1 \mathrm{~L} \cdot \mathrm{min}^{-1} \cdot \mathrm{m}^{-2}$, with a normal pulmonary vascular resistance index ranging from 0.3 to 2.3 Wood

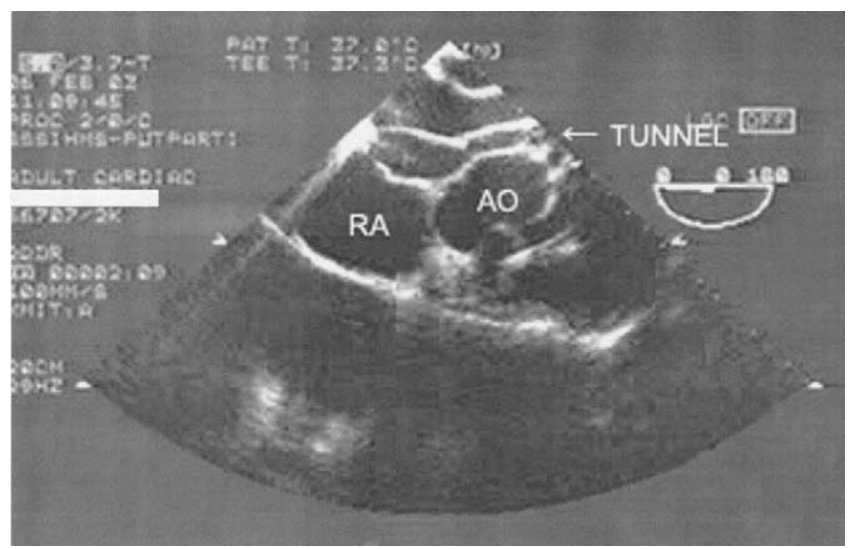

Figure 1. Preoperative transesophageal echocardiogram (patient 3) showing posterior type of tunnel from the left coronary sinus to the right atrium (RA). AO, Aorta.

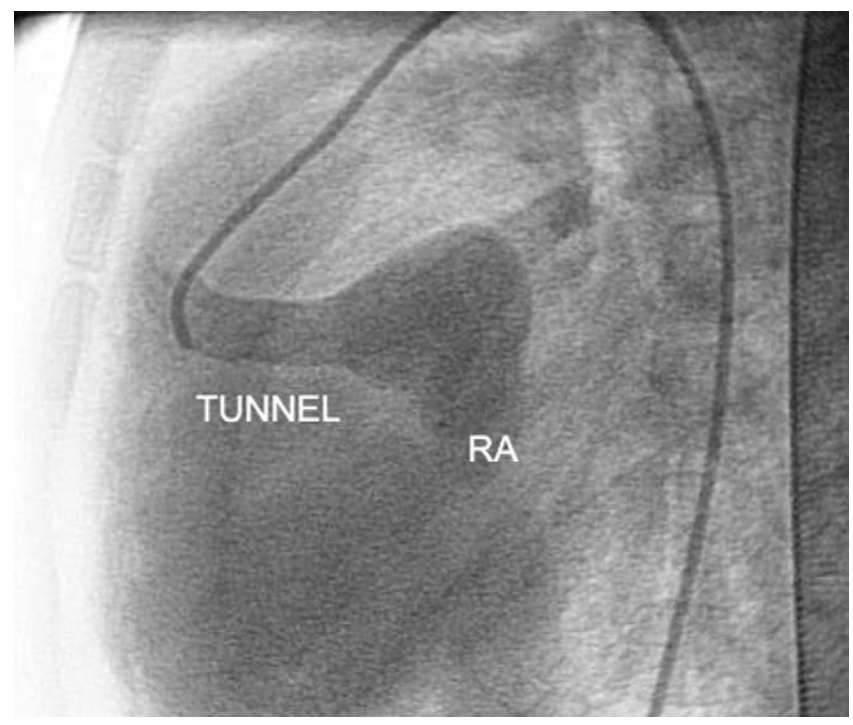

Figure 2. Anterior type of tunnel, $90^{\circ}$ lateral view (patient 5). $R A$, Right atrium.

units. Ascending aortography done in the left anterior oblique $60^{\circ}$, with cranial $20^{\circ}$, lateral $90^{\circ}$, and right anterior oblique $30^{\circ}$ views showing a tunnel-like structure arising from the left coronary sinus in 6 patients and from the right coronary sinus in 3 patients and opening into the superior vena cava-right atrial junction in 5 patients and the body of the right atrium in 4 patients (Figures 2-5). Selective coronary angiography revealed normal coronary arteries

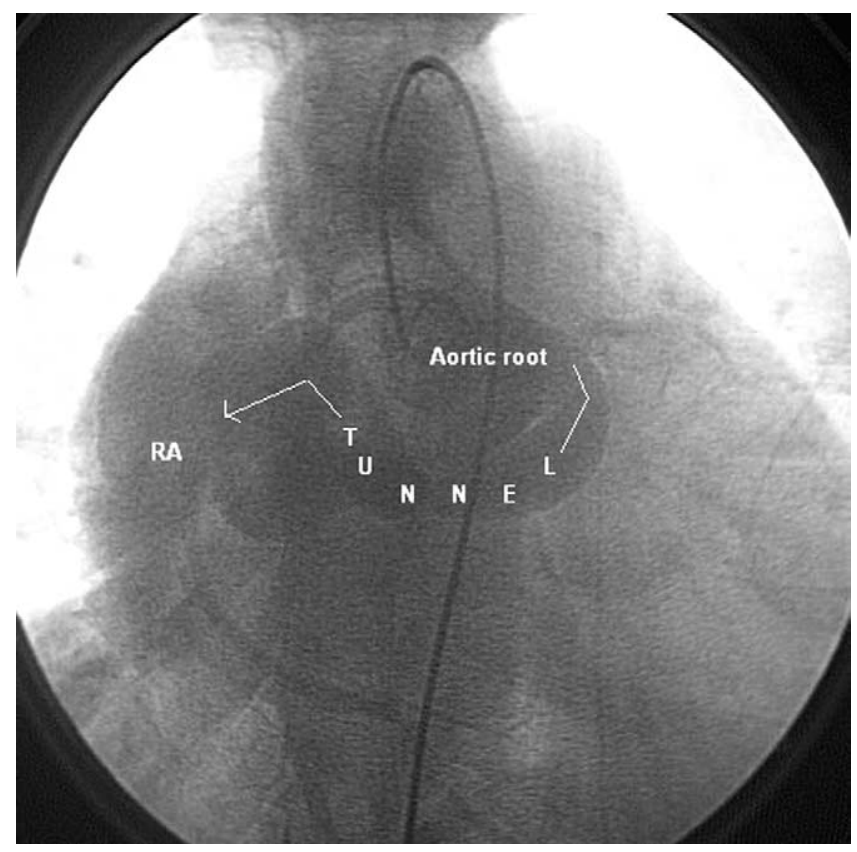

Figure 3. Posterior type of tunnel with normal coronaries, frontal view (patient 6). RA, Right atrium. 


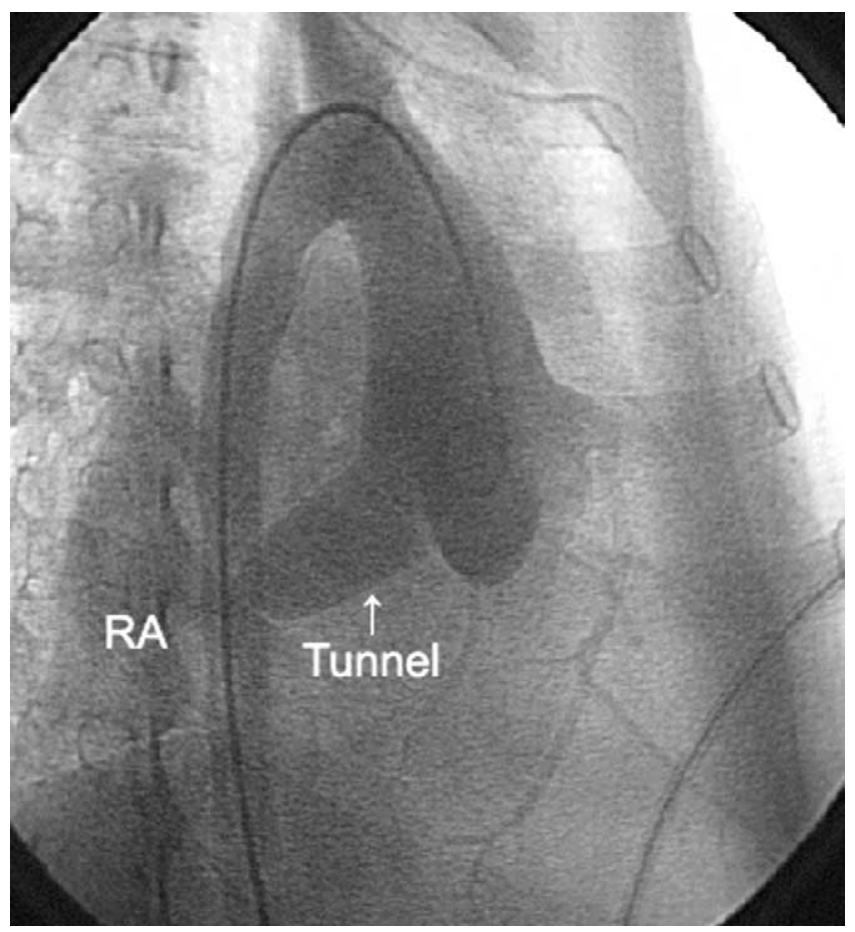

Figure 4. Posterior type of tunnel, $30^{\circ}$ right anterior oblique view (patient 4). RA, Right atrium.

arising from respective sinuses (Figure 3) and absence of any coronary fistula arising from the tunnel.

In all the patients, surgical approach was decided on the basis of the location of the tunnel in relation to the ascending aorta. For the anterior type of tunnels encountered in 3 patients, 1 patient was treated with double ligation of the tunnel after achievement of hypotensive anesthesia without the need for cardiopulmonary bypass. In the second patient because the right coronary artery was arising from the tunnel, the tunnel was ligated and plicated from outside distal to the origin of the right coronary artery, and the right atrial end was directly closed on cardiopulmonary bypass. The third patient underwent successful coil embolization (Figure 6). In the patients with the posterior type of tunnel, cardiopulmonary bypass was established after cannulating the ascending aorta and both venae cavae. After cardioplegic arrest, the ascending aorta was opened transversely. The aortic end of the tunnel was closed with a Dacron patch in 5 patients, and a polytetrafluoroethylene patch (Gore-Tex patch; W. L. Gore \& Associates, Inc. Flagstaff, Ariz) was used in the sixth patient, staying away from the left coronary ostium. The right atrial end was directly closed.

Details of morphology, origins of coronary arteries, and treatment offered in all 9 patients and that of cases reported in the literature are summarized in Tables 1 and $2,{ }^{1-3}$ respectively.

\section{Results}

The total intensive care unit stay was 3 to 6 days (mean, 4 days), and hospital stay was from 1 to 18 days (mean, 9 days). There was one perioperative mortality in the entire

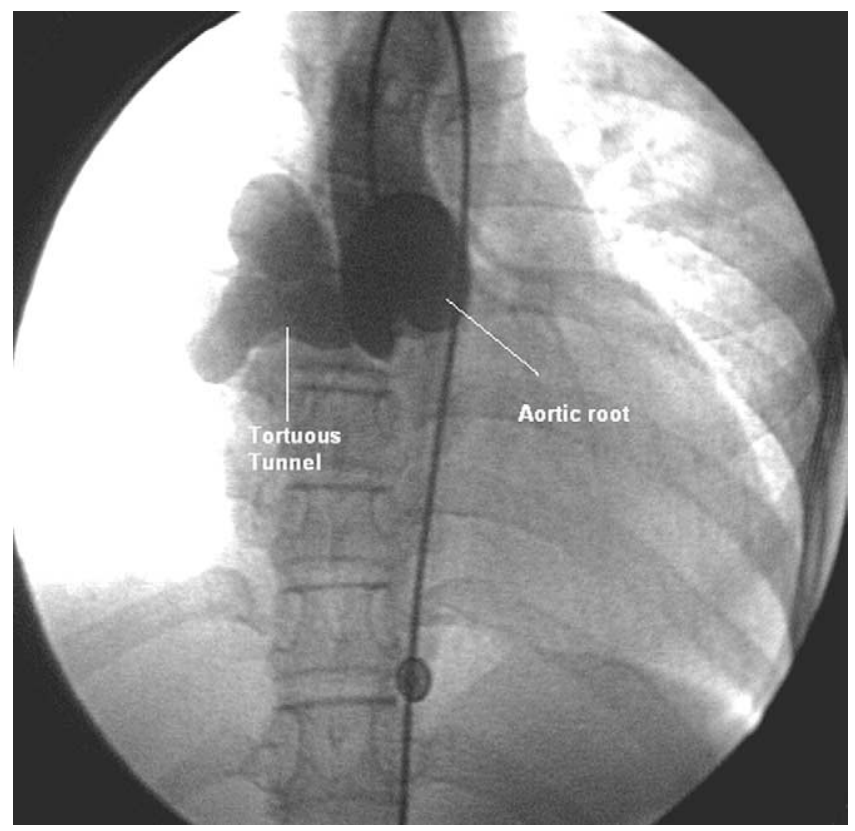

Figure 5. Posterior type of tunnel, frontal view (patient 9).

series. During our early experience, one patient in whom the aortic end was closed along with coronary opening and in whom coronary artery bypass was done to the left anterior descending coronary artery and obtuse marginal died intraoperatively because of intractable ventricular fibrillation. In all other patients, 2D echocardiography performed before

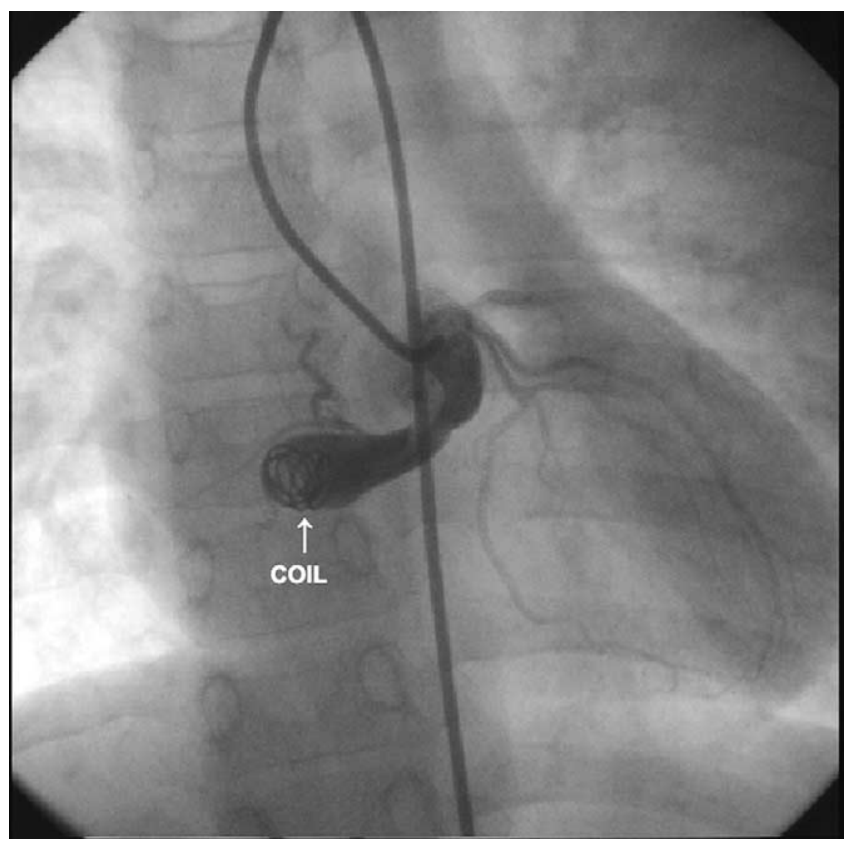

Figure 6. Coil embolization of anterior type of tunnel (patient 8). 
TABLE 1. Overview of demography of patients and treatment offered

\begin{tabular}{|c|c|c|c|c|c|c|}
\hline Age $(y) /$ sex & $\begin{array}{l}\text { Associated } \\
\text { lesions }\end{array}$ & Tunnel type & Origin & Termination & Coronary origin & Treatment offered \\
\hline $9 / F$ & PDA & Posterior & LCS & SVC-RA junction & Separate & $\begin{array}{l}\text { Direct closure of RA end, PTFE } \\
\text { patch closure of aortic end }\end{array}$ \\
\hline $45 / F$ & ASD OS & Posterior & LCS & Posterior wall of limbus & Proximal part of tunnel & $\begin{array}{l}\text { Direct closure of RA end, Dacron } \\
\text { patch closure of aortic end } \\
\text { CABG-LITA-LAD, SVG-OM }\end{array}$ \\
\hline $23 / F$ & None & Posterior & LCS & SVC-RA junction & Proximal part of tunnel & $\begin{array}{l}\text { Direct closure of RA end, Dacron } \\
\text { patch closure of aortic end }\end{array}$ \\
\hline $15 / \mathrm{M}$ & ASD OS & Posterior & LCS & Posterior wall of limbus & Separate & $\begin{array}{l}\text { Direct closure of RA end, Dacron } \\
\text { patch closure of aortic end }\end{array}$ \\
\hline $18 / \mathrm{M}$ & None & Anterior & RCS & $\begin{array}{l}\text { Posterolateral wall of } \\
\text { SVC-RA junction }\end{array}$ & Proximal part of tunnel & $\begin{array}{l}\text { Direct closure of RA end, tunnel } \\
\text { ligated distal to RCA ostium } \\
\text { and plicated near aortic end }\end{array}$ \\
\hline $42 / \mathrm{M}$ & None & Posterior & LCS & $\begin{array}{l}\text { Posterior wall of SVC- } \\
\text { RA junction }\end{array}$ & Proximal part of tunnel & $\begin{array}{l}\text { Direct closure of RA end, Dacron } \\
\text { patch closure of aortic end }\end{array}$ \\
\hline $3 / \mathrm{M}$ & None & Anterior & RCS & Roof of RA & Proximal part of tunnel & $\begin{array}{l}\text { Doubly ligated under hypotensive } \\
\text { anesthesia }\end{array}$ \\
\hline $10 / \mathrm{M}$ & None & Anterior & RCS & Roof of RA & Separate & Coil embolization \\
\hline $17 / F$ & None & Posterior & LCS & SVC-RA junction & Separate & $\begin{array}{l}\text { Direct closure of RA end, Dacron } \\
\text { patch closure of aortic end }\end{array}$ \\
\hline
\end{tabular}

PDA, Patent ductus arteriosus; $L C S$, left coronary sinus; $S V C$, superior vena cava; $R A$, right atrium; $P T F E$, polytetrafluoroethylene; $A S D$ OS, ostium secundum atrial septal defect; $C A B G$, coronary artery bypass grafting; $L I T A$, left internal thoracic artery; $L A D$, left anterior descending coronary artery; $S V G$, saphenous vein graft; $O M$, obtuse marginal; $R C S$, right coronary sinus; $R C A$, right coronary artery.

discharge showed no residual shunts and good biventricular function.

On follow-up at 3 months, 6 months, and 1 year, all patients were asymptomatic, as revealed by means of 2D echocardiography, there were no residual shunts, and there was good biventricular function. The last patient had only 3 months' follow-up, at which time 2D echocardiography did not reveal any residual shunt and showed wellpreserved biventricular function. The very first patient was treated with polytetrafluoroethylene patch closure of the aortic end of the tunnel and direct closure of the right atrial opening. Because of rarity of the disease, this patient underwent cardiac catheterization and angiography on follow-up at 3 months, which showed no residual shunts and normal hemodynamics.

\section{Discussion}

Eight cases of ARAT were reported in the literature until May 2004. ${ }^{5}$ Nine such cases were treated at our institution. Embryologic background and cause for this anomaly are not clear. The tunnel-like vascular extracardiac communication between the aortic root and the right atrium arose from any of the 3 sinuses of Valsalva. ${ }^{1-5}$ Probable cause for this condition seems to be a congenital deficiency of the elastic lamina in the aortic media. Because of high aortic pressure, defective area in the aortic wall forms an extracardiac tunnel, leading to gradual enlargement and rupture into the right atrium because of anatomic proximity and low filling pressure. We believe this might explain why tunnels from the right sinus run anteriorly and tunnels from the left sinus lead posteriorly. Review of the literature implicates fistulous involvement of the sinus node artery arising separately from the left sinus of Valsalva. This fails to explain the case in which the tunnel arose from the noncoronary sinus of Valsalva. ${ }^{1}$

This aorto-right atrial communication behaves like a left-to-right shunt at the atrial level. Although reports in the literature reveal all patients to be asymptomatic, except for one patient presenting with palpitation, all our patients were symptomatic. The most common symptoms were shortness of breath, palpitation, and recurrent respiratory tract infections. On physical examination, all patients had a continuous murmur at the right parasternal border.

Contrary to the cases reported in the literature, 3 of our 9 patients had associated cardiac anomalies, the most common being the secundum type of atrial septal defect.

The single diagnostic feature is demonstration of this distinct tunnel arising from one of the aortic sinuses of Valsalva and having an extracardiac course and entering into the right atrium. Two-dimensional echocardiography can differentiate a coronary cameral fistula by visualizing both coronary origins separately away from the tunnel or the tunnel itself. ${ }^{2}$ Differentiation from a ruptured sinus of Valsalva aneurysm is done by demonstrating a tunnel with an extracardiac course. ${ }^{2}$ Aortography also helps to differentiate from coronary cameral fistula. Selective coronary 
TABLE 2. Characteristics of patients in the literature

\begin{tabular}{|c|c|c|c|c|c|c|}
\hline Author (year) & Age/sex & Type & Origin & Termination & Coronary origin & Treatment offered \\
\hline Otero Coto et al ${ }^{1}(1980)$ & $25 \mathrm{y} / \mathrm{M}$ & Anterior & NCS & Lateral aspect of $\mathrm{RA}$ & Separate & $\begin{array}{l}\text { Interrupted suture closure of aortic } \\
\text { end. RA end closed from inside } \\
\text { the aneurysm }\end{array}$ \\
\hline Rosenberg et $\mathrm{al}^{2}$ (1986) & $7 \mathrm{y} / \mathrm{F}$ & Posterior & LCS & Roof of RA & Separate & $\begin{array}{l}\text { Aortic end closed with running } \\
\text { suture from within the tunnel, } \\
\text { and RA end was not closed }\end{array}$ \\
\hline Rosenberg et $\mathrm{al}^{2}$ (1986) & $6 \mathrm{mo} / \mathrm{F}$ & Posterior & LCS & $\begin{array}{l}\text { Superior aspect } \\
\text { of } R A\end{array}$ & $\begin{array}{l}\text { Proximal part of } \\
\text { tunnel }\end{array}$ & $\begin{array}{l}\text { Aortic end was closed with a } \\
\text { running suture and direct } \\
\text { closure of RA end }\end{array}$ \\
\hline Rosenberg et $\mathrm{al}^{2}$ (1986) & $15 \mathrm{y} / \mathrm{M}$ & Posterior & LCS & SVC-RA junction & Separate & $\begin{array}{l}\text { Aortic end was closed with a } \\
\text { running suture, and RA end was } \\
\text { not closed }\end{array}$ \\
\hline Rosenberg et $\mathrm{al}^{2}$ (1986) & $8 \mathrm{mo} / \mathrm{M}$ & Posterior & LCS & SVC-RA junction & $\begin{array}{l}\text { Proximal part of } \\
\text { tunnel }\end{array}$ & $\begin{array}{l}\text { Aortic end was closed with a } \\
\text { running suture, and RA end was } \\
\text { not closed }\end{array}$ \\
\hline Kalangos et al ${ }^{3}(2000)$ & $18 \mathrm{y} / \mathrm{M}$ & Posterior & LCS & Roof of RA & Separate & $\begin{array}{l}\text { Direct closure of RA and aortic } \\
\text { ends with excision of the tunnel }\end{array}$ \\
\hline Kalangos et $\mathrm{al}^{3}(2000)$ & $7 \mathrm{y} / \mathrm{M}$ & Posterior & LCS & Roof of RA & Separate & Ligated at both ends \\
\hline Turkay et al (2003) & $29 \mathrm{y} / \mathrm{M}$ & Anterior & RCS & Lateral aspect of RA & $\begin{array}{l}\text { Proximal part of } \\
\text { tunnel }\end{array}$ & $\begin{array}{l}\text { Direct closure of RA and aortic } \\
\text { ends and implantation of right } \\
\text { coronary ostium into the aortic } \\
\text { sinus }\end{array}$ \\
\hline
\end{tabular}

$N C S$, Noncoronary sinus; $R A$, right atrium; $L C S$, left coronary sinus; $R C S$, right coronary sinus.

angiography is essential to demonstrate the coronary ostia. In cases in which the coronary ostia cannot be cannulated or located, electron tomography can be used, and it also has the advantage of being noninvasive. ${ }^{5}$

Careful review of all the cases reveals that morphologically there are 2 distinct types of tunnels, anterior and posterior, according to their origin and course in relation to the ascending aorta, as demonstrated on ascending aortography. In all 6 patients in whom the tunnel originated in the left sinus of Valsalva, the tunnel had a course posterior to the ascending aorta before emptying into the right atrium. In all 3 patients in whom the tunnel arose from right sinus of Valsalva, the tunnel took a course anterior to the ascending aorta before joining the right atrium.

Various management options are available, depending on the type of tunnel, its caliber, course, and location of the coronary ostia in relation to the aortic orifice of the tunnel.

From our limited experience, coil embolization of the tunnel is recommended, provided the opening of the right atrial end is small, coil size is available for the size of the tunnel, and there is a constriction in the course of the tunnel.

Ligation of the tunnel can be done near the aortic end after achievement of hypotensive anesthesia for anteriorly located tunnels and between the superior vena cava and aorta as close to the aorta as possible for posteriorly located tunnels provided the coronary ostia are not compromised. This is an attractive off-pump approach.
Surgical closure of the aortic end is achieved with a patch closure, keeping in mind the location of the coronary ostia. The patch is oriented so as not to compromise the origin of the coronary artery.

If coronary artery origin is deep in the tunnel, a viable option is to ligate the tunnel at the aortic end and reimplant the coronary artery with a button of the tunnel wall into the respective sinus of Valsalva, with direct closure of the right atrial end. In retrospect, ligation of the tunnel at the aortic end and reimplantation of the coronary ostium with a part of the tunnel wall would have been life saving for one patient who died intraoperatively.

All patients were discharged from the hospital between 1 and 18 days, and their follow-up revealed them to be asymptomatic and without residual shunt. In patients whose tunnels were ligated or coil embolized, the proximal part of the tunnel did not show any clots or aneurysm formation.

\section{Conclusions}

ARAT is a congenital anomaly characterized by an extracardiac tunnel-like vascular communication arising from any one of the aortic sinuses and emptying into the right atrium. The preference for rupture into the right atrium is unclear. The constantly observed tendency for tunnels arising from the right sinus to run an anterior course and tunnels arising from left sinus to take a posterior course seems to be due to direct anatomic proximity to the low-pressure right 
atrium. Clinical presentation is characterized by a continuous murmur at the right parasternal border. This clear-cut clinical entity can be differentiated from other commonly encountered aorto-right atrial communications, like ruptured sinus of Valsalva aneurysm and coronary cameral fistula, by 2D- echocardiography and transesophageal echocardiography. Ascending aortography combined with selective coronary angiography is the best diagnostic tool, showing the tunnel taking its origin from one of the sinuses of Valsalva and entering the right atrium through an extracardiac tortuous link. Ascending aortography and selective coronary angiography are essential tools in planning the line of treatment. Electron tomography or magnetic resonance angiography might be additional noninvasive tools for diagnosis. Surgical closure should be recommended soon after diagnosis because continued patency of the tunnel might predispose patients to risk of volume overload of both ventricles, congestive cardiac failure, pulmonary vascular disease, aneurysm formation, infective endocarditis, spon- taneous rupture, and increased surgical mortality with age. Coil embolization is a useful modality in selective cases. Surgical options include plication of the tunnel or patch closure of aortic origin with direct closure of the atrial opening. If the origin of the coronary artery is deep in the tunnel, it should be reimplanted with a part of the tunnel into the respective sinus of Valsalva.

\section{References}

1. Otero-Coto E, Caffarena JM, Such M, Marques JL. Aorta-right atrial communication: report of an unusual case. J Thorac Cardiovasc Surg. 1980;80:941-4.

2. Rosenberg H, Williams WG, Trusler GA, Smallhorn J, Rowe RD, Moes $\mathrm{CAF}$, et al. Congenital aortico-right atrial communications. J Thorac Cardiovasc Surg. 1986;91:841-7.

3. Kalangos A, Beghetti M, Vala D. Aortico-right atrial tunnel. Ann Thorac Surg. 2000;69:35-7.

4. Ooman A, Mao R, Krishnan P, Girinath MR. Congenital aortocaval fistula to superior vena cava. Ann Thorac Surg. 2000;72:91-3.

5. Turkay C, Golbasi I, Belgi A, Tepe S, Bayezid O. Aorta-right atrial tunnel. J Thorac Cardiovasc Surg. 2003;125:1058-60.

\section{JTCVS On-Line Manuscript Submission and Review}

The Journal of Thoracic and Cardiovascular Surgery requires authors and reviewers to submit all new and revised manuscripts and reviews via Editorial Manager. Point your browser to http://jtcvs.editorialmanager.com, log in as author or reviewer (as appropriate), and follow the instructions provided.

To retrieve your username and password, click "Forget your password?" on the Editorial Manager log-in page.

If you have questions or experience problems uploading your manuscript or review, please contact the editorial office:

Telephone: 215-762-1854

E-mail: jtcvs@drexel.edu 